\begin{tabular}{|l|l|l|l|l|}
\hline Crystal Res. \& Technol. & 19 & 1984 & 5 & $613-616$ \\
\hline
\end{tabular}

M. Winkler, C. Genzel, L. Parthier, P. Gillie

Scktion Physik, Humboldt-Universität, Berlin, DDR

\title{
Double Crystal Topographic Investigations of PbTe Grown by the Travelling Heater Method (THM)
}

THM-grown PbTe and PbTe:Tl were examined near the $(n,-n)$-position by means of $\mathrm{X}$-ray double crystal arrangement. The half-width of the rocking curves of $\mathrm{Tl}$ doped $\mathrm{Pb} \mathrm{Te}$ is larger than that of undoped PbTe by factor two. Long range and local lattice plane distortions, as well as disturbances induced during preparation, in the from of dislocation slip lines and greatly disoriented areas were observed.

THM-gezüchtetes PbTe und PbTe:Tl wurden mittels Röntgen-Doppelkristallanordnung nahe der $(n,-n)$-Stellung untersucht. 1)ie Rockingkurvenhalbwertsbreite von Tl-dotiertem PbTe ist um den Faktor zwei größer als bei undotiertem PbTe. Großräumige und lokale Netzebenenverzerrungen, sowie präparationsinduzjerte Störungen in Form von Versetzungsgleitlinien und stark desorientierten Bereichen wurden beobachtet.

\section{Introduction}

The investigation of the defect structure of PbTe substrate slices is indispensable for understanding the effects of the conditions of THM-growth (WoLFF, MLAVSKY; SCHIKora et al.), the surface preparation (ENGEL), and the interface effects regarding epitaxy. By making use of the double crystal arrangement (DCA) it is possible to obtain a non-destructive view of long range and nicrosopic disturbances of the real structure. They are low angle grain boundaries, lattice plane bendings, i.e., distributions of orientation, wide dislocation arrangements, inhomogeneities of the distribution of dopants.

In this paper first results of THM-grown undoped and Tl-doped $\mathrm{PbTe}$ shall be represented.

\section{Experimental}

Use was made of a DCA near the $(n,-n)$ arrangement. As first crystal (111)-Si was employed. (100)-PbTe was analyzed. For CuKa radiation the reflex pair Si-5l l $\left(2 \theta=95.00^{\circ}\right)$, I'bTe-620 $\left(2 \theta=98^{\circ} 10^{\prime}\right)$ corresponds. In this case a residual dispersion of $36^{\prime \prime}$ ensues. The angle of incidence is $8.5^{\circ}$, i.e., with regard to $\mathrm{Si}$ there exists an asymmetrical reflection.

Rocking curves were registered and compared. In every case identical collimation conditions were employed (thin-shielded tapes in the diffraction plane). Series of topographs in defined crystal positions were made.

\section{Results and discussion}

Figure 1 shows typical results of the measurements of rocking curves with regard to undoped and Tl-doped $\mathrm{PbTe}$. The significant difference in the half width approximately around factor two characterizes a generally worse perfection of the Tl-doped 


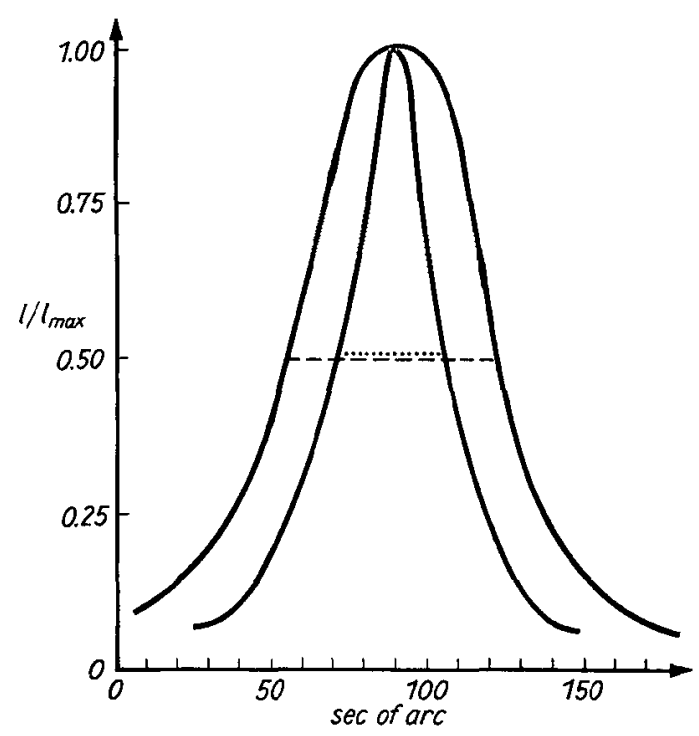

Fig. 1. Double crystal rocking curves of undoped and Tl-doped PbTe; half widths $35^{\prime \prime}$ (PbTe .....) and 65" (PbTe:Tl -...)

material. That is we can start out from the idea that the Tl is incorporated in such a way that during the process of growth distinct distributions of orientation and/or lattice parameters occur. It is remarkable that a half-width difference approximately around factor two was observed when (620) lattice plane families in positions caused by turn of $90^{\circ}$ round $[100]$-axis $($ e.g., 620, 602), were used. This is valid with regard to both $\mathrm{PbTe}$ and $\mathrm{PbTe}$ :Tl. In consideration of different possible causes a true preferred orientation of the disturbances does not seem to be impossible for this effect. Double crystal (DC) topographs in, e.g., 620 and $60 \overline{2}$ reflections point to this effect (see Fig. 2). Attention should be paid to the distinctly larger extent of reproduction in a defined position regarding the 602 reflection.
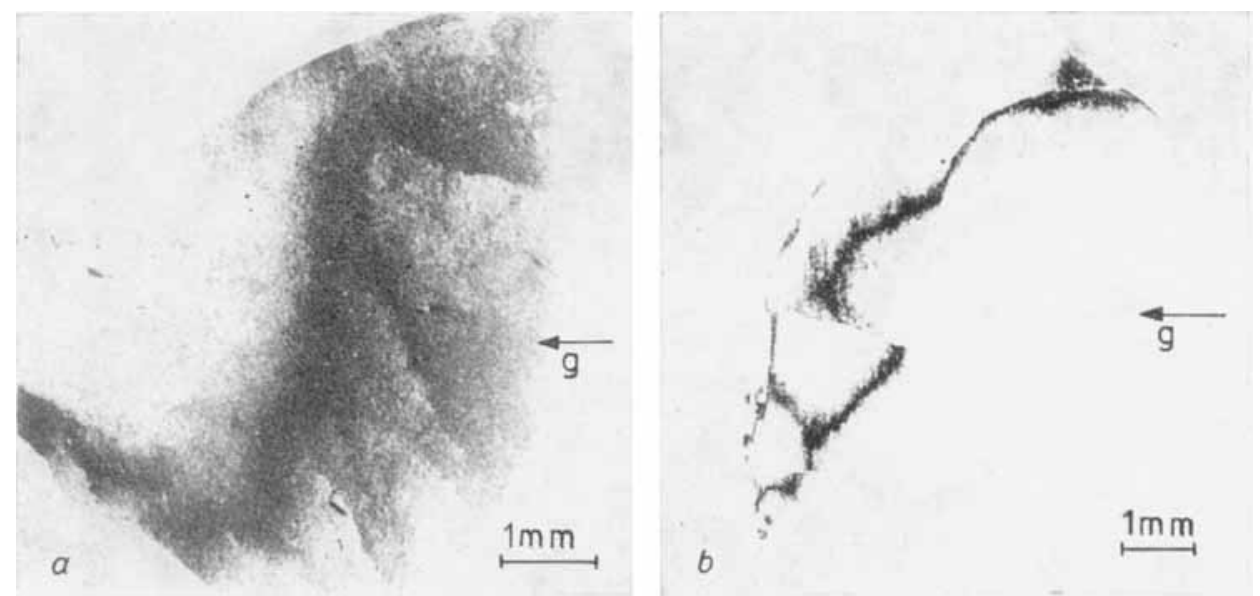

Fig. 2. 511/620 double erystal topographs of undoped PbTe; (a) (60) 2 )-reflex (characteristic wide range topogram), (b) (620)-reflex (typical stripclike contrast) 
Figure 3 shows typical DC topograms of the examined specimens, composed of discrete single frames. What is striking is the more or less stripelike general impression of the single frame. Figure 4 is to indicate our schematic conception of a distribution of orientation in this case (abrupt edges for reasons of representation).
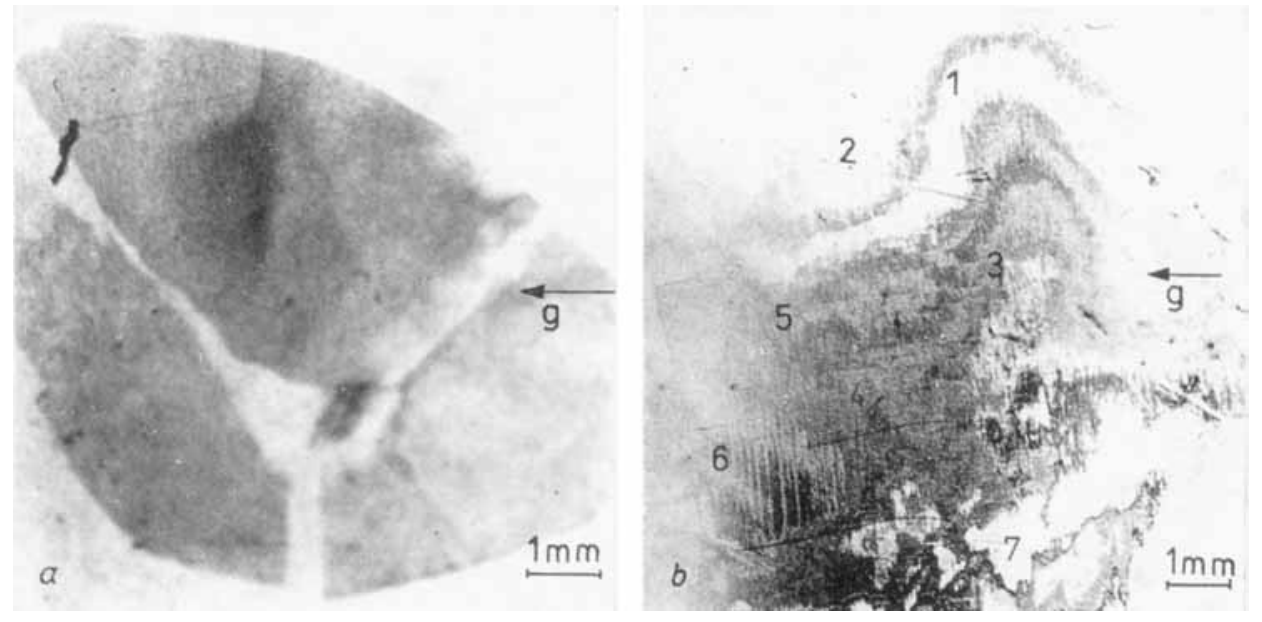

Fig. 3. Double crystal topographs caused by exposure one upon another in select angular positions (turn of $27^{\prime \prime}$ each), (a) undoped PbTe, 2 positions, (b) doped PbTe, 6 positions

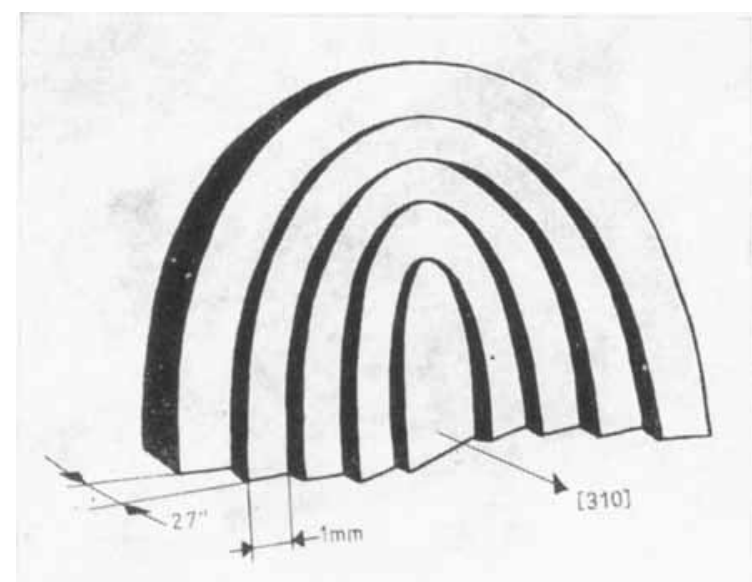

Fig. 4. Schematic presontation of lattice plane distribution of oricutation as in Figure $3 \mathrm{~b}$ above

The relative movement of the imaging schlieren when they were bent in different positions at one and the same net plane family after an azimuthal turn of $180^{\circ}$ of the crystal (KIKUTA et al.) resulted clearly in a distribution of orientation as cause of the reflex movement for the undoped case. In the case of the doped $\mathrm{PbTe}$ peculiar ringlike effects appear in addition which contract or diverge depending on the position of the crystal. Also in this case distribution of orientation seems to be predominant, but a contribution of a change of the lattice parameter cannot be excluded.

41 Crystal Res. \& Technol., Vol. 19, No. 5 
Figure $3 \mathrm{~b}$ aptly demonstrates the multitude of further defects regarding the substrate material. We interpret the single images as follows:

(1) extensive lattice distortions,

(2) reproduction of scratches which were produced during preparation and not noticeable by optical microscopy,

(3) lamelloid striping the nature of which has not been clarified so far and which appeared in connection with this reflex only,

(4) possible single dislocations parallel with the surface,

(5) local disorientations or lattice constant oscillations,

(6) sum effect caused by a dislocation glide system which was stimulated in the process of preparation (Pietscr et al.),

(7) ring-like effect caused by disguise of distribution of orientation due to the process of electrospark separation.

For the local disorientations a radius of curvature of $8 \mathrm{~m}$ (PbTe) and $4 \mathrm{~m}$ (PbTe:Tl) can be indicated.

\section{Conclusions}

THM growth and preparation result in crystals and slice surfaces with a strongly distorted lattice. It was shown that multiple kinds of disturbances can be proved by the use of DCA. The incorporation of dopants apparently results in additional disturbances. In our opinion epitaxy and production of infrared optical devices are in particular negatively influenced by the local changes of orientation as well as the general destruction - near the surface - of the perfection due to the preparation.

\section{References}

ENGEL, A.: Kristall und Technik 15, 1439 (1980)

Kikuta, S., Kohra, K., Sugrita, Y.: Jap. J. Appl. Physics 5, 1047 (1966)

Pretsch, U., MÜhlberg, M., Brerger, H.: Kristall und Technik 15, K 7 (1980)

Schikora, D., Parthier, T., Rudolph, P.: Proceedings of the Furopean Meeting on Crystal Growth '82, Prague, August 1982, p. 73, B 4

Wolfy, G. A., Mlavsky, A. I.: Travelling solvent techniques; in Crystal Growth ed. Goovman, New York 1974

(Received September 17, 1983)

Authors' address:

M. Winkler, C. Genzel, L. Parthier, P. Gille

Sektion Physik der Humboldt-Universität, Bereich 11 - Kristallographie

DDR-1040 Berlin

Invalidenstraße 43 